\title{
Paper-based electroanalytical devices with an integrated, stable reference electrode
}

\section{Citation}

Lan, Wen-Jie, E. Jane Maxwell, Claudio Parolo, David K. Bwambok, Anand Bala Subramaniam, and George M. Whitesides. 2013. "Paper-Based Electroanalytical Devices with an Integrated, Stable Reference Electrode." Lab Chip 13(20): 4103-4108.

\section{Published Version}

doi:10.1039/c3lc50771h

\section{Permanent link}

http://nrs.harvard.edu/urn-3:HUL.InstRepos:12361278

\section{Terms of Use}

This article was downloaded from Harvard University's DASH repository, and is made available under the terms and conditions applicable to Open Access Policy Articles, as set forth at http:// nrs.harvard.edu/urn-3:HUL.InstRepos:dash.current.terms-of-use\#OAP

\section{Share Your Story}

The Harvard community has made this article openly available.

Please share how this access benefits you. Submit a story.

Accessibility 


\section{Paper-Based Electroanalytical Devices with an Integrated, Stable}

\section{Reference Electrode}

Wen-Jie Lan ${ }^{\mathrm{a}}$, E. Jane Maxwell ${ }^{\mathrm{a}}$, Claudio Parolo ${ }^{\mathrm{a}, \mathrm{b}}$, David K. Bwambok ${ }^{\mathrm{a}}$, Anand Bala Subramaniam ${ }^{\mathrm{a}}$, and George M. Whitesides ${ }^{\mathrm{a}, \mathrm{c}^{*}}$

${ }^{a}$ Department of Chemistry and Chemical Biology, Harvard University, Cambridge, MA 02138

${ }^{\mathrm{b}}$ Nanobioelectronics \& Biosensors Group, Institut Català de Nanotecnologia, CIN2, Campus UAB, Barcelona, Spain

${ }^{c}$ Wyss Institute for Biologically Inspired Engineering, Harvard University, Cambridge, MA 02138

*Corresponding author E-mail: gwhitesides@gmwgroup.harvard.edu

Target Journal: Angewandte Chemie Communication 
With the rapid development of portable lab-on-a-chip devices, miniaturized electrochemical systems have attracted increasing attention, because they are sensitive, insensitive to light levels, independent of human interpretation of color, easily interfaced with the web, and require only a small volume (several $\mu \mathrm{L}$ ) of sample. ${ }^{1}$ We and others are exploring Electrochemical Paper-based Analytical Devices (EPADs) ${ }^{2-6}$ (see Table S1 for additional references). EPADs often employ a printed $\mathrm{Ag} / \mathrm{AgCl}$ "pseudo-reference electrode" whose potential ( $\left.\mathrm{AgCl}(s)+e^{-} \rightleftarrows \mathrm{Ag}(s)+\mathrm{Cl}^{-}(a q)\right)$ depends on the concentration of chloride ions in the sample solution. ${ }^{7}$ These devices cannot maintain a stable potential unless a high and stable concentration of soluble chloride salts is added to the sample prior to measurement. This requirement limits their general applicability.

Several commercial hand-held micro-electrochemical diagnostic systems (for example, the i-STAT ${ }^{\circledR}$ clinical analyzer ${ }^{8}$ ) determine analytes in human blood through amperometry or potentiometry; these systems use miniaturized reference electrodes that resemble scaled-down versions of conventional glass-bodied $\mathrm{Ag} / \mathrm{AgCl}$ reference electrodes. These three-dimensional miniaturized reference electrodes require sealing of an inner reference solution with a protective layer, and the implementation of a micro-junction between the reference solution and the sample. ${ }^{9}$ They may require complicated lithography, or chip-manufacturing techniques.

Paper has been used as an integral component in electrochemical cells (for example, historically as a salt bridge to connect the oxidation and reduction half-cells in conventional galvanic cells, or more recently as a matrix to hold the internal reference solution in a separate reference electrode). ${ }^{10}$ An integrated paper-based device that includes an accurate reference electrode would enable the full range of electrochemical measurements (e.g., for voltammetry, and in measurements of $\mathrm{pH}$ and concentrations of ions) in a low-cost and disposable format. A 
reference electrode of this kind has not yet been described.

Here we report the design of a well referenced Electrochemical Paper-based $\underline{\text { Analytical }}$ Device (herein after referred to as a "rEPAD", Figure 1) comprising a sample zone, a reference zone, and a connecting microfluidic channel that includes a mixing zone. This arrangement allows ionic contact between the sample and the reference solutions, but - due to the slow (diffusive), convection-free transport of ions in the liquid-filled paper channels - prevents interchange of ions between the sample and reference zones. These rEPADs provide a stable and well-defined reference potential for direct and accurate measurements of analytes; their performance is comparable to conventional electrochemical cells that contain commercial glass-bodied $\mathrm{Ag} / \mathrm{AgCl}$ reference electrodes, and they offer several advantages: (i) they are made of paper, which is inexpensive, lightweight, portable, less fragile than glass, and easily disposable (for single use), (ii) they eliminate the need for storage of the electrode in a solution of $\mathrm{KCl}$, (iii) they are fabricated in a planar structure, and thus appropriate for mass fabrication with roll-to-roll printing, and (iv) they can be easily integrated into systems that permit multiplexed analysis or pipette-free sampling.

Figure 1 shows the geometry of the rEPAD. We defined the microfluidic channels (Figure 1a) by wax printing, ${ }^{11}$ and added electrodes to the device by stencil-printing carbon and $\mathrm{Ag} / \mathrm{AgCl}$ inks in the sample and reference zones, ${ }^{3}$ respectively. The resulting devices can be used without further modification (for experiments lasting $<6 \mathrm{~min}$ ), or can be sealed with tape to minimize evaporation (for longer experiments). The Supporting Information (SI) provides additional details.

When two different solutions are added to the sample and reference zones, either by pipetting $(\sim 10 \mu \mathrm{L}$, for devices of the type shown in Figure 1) or dipping (for the devices shown 
Figure 1. Schematic illustration ( $a$ and b) and photographs (c and d) of a referenced Electrochemical Paper-based Analytical Device (rEPAD). The paper was patterned by wax printing to define the sample zone, central contact zone, reference zone, and microfluidic channels. The sample and reference zones include stencil-printed carbon and $\mathrm{Ag} / \mathrm{AgCl}$ electrodes, respectively. The dashed lines in (d) indicate the approximate boundaries of the carbon and $\mathrm{Ag} / \mathrm{AgCl}$ ink printed on the back. 

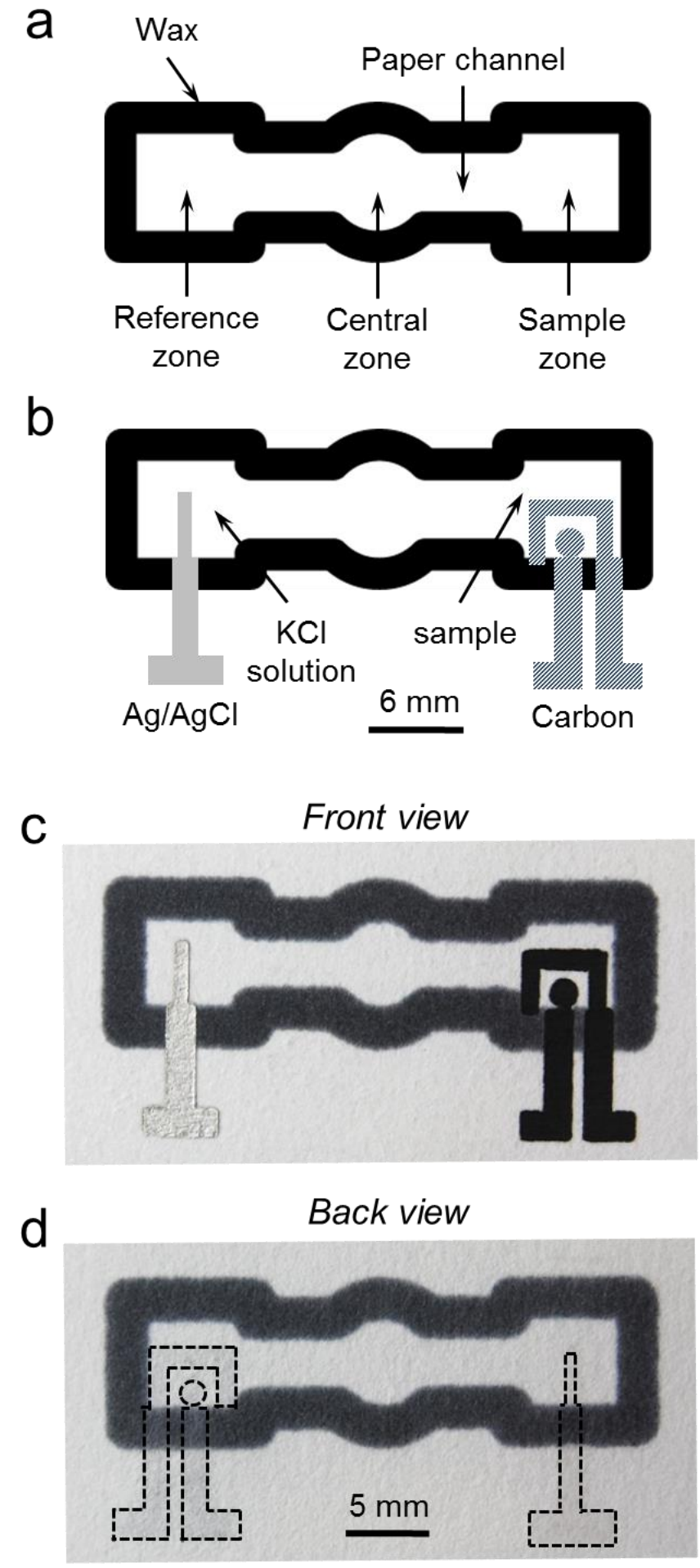
in Figure 2), capillarity pulls the liquids (aqueous solution of electrolytes such as potassium chloride) along the channels to the central zone. Once the liquids meet and completely saturate the hydrophilic network of cellulose fibers, capillary-driven flow and bulk convective transport of liquid stop. Instead, diffusional transport, due to concentration gradients across the interface between the two liquids, dominates the mass transport of ions within the device (subtle differences in the hydrodynamic pressure between the zones might, in principle, result in mass transport by convection, but we have found this contribution to be negligible - see SI).

Because the accuracy of the rEPAD depends on the concentration of the solutions in the reference and sample zones, and not in the zone of contact, we undertook experiments and calculations to determine if the sample and reference have constant concentrations within their respective zones. We sealed the tops and bottoms of the devices with transparent tape to minimize evaporation, and placed a solution of cobalt chloride $\left(\mathrm{CoCl}_{2}\right.$, pink) in contact with the left inlet of the device, and copper sulfate $\left(\mathrm{CuSO}_{4}\right.$, blue $)$ with the right inlet. The pink $\mathrm{Co}^{2+}$ ions arrived (by wicking) at the zone of contact in less than 15 minutes (Figure 2a). Following this initial rapid transport of liquid, we observed no pink $\mathrm{Co}^{2+}$ diffusing into the right zone for 2 hours, and, correspondingly, no blue $\mathrm{Cu}^{2+}$ diffusing into the left zone. After 2 hours, the device began to dry by evaporation, as indicated by the color change. The times required for both wicking and evaporation were shorter ( $<1 \mathrm{~min}$ and $\sim 20 \mathrm{~min}$, respectively) in devices that were not sealed with tape (Figure S1 and SI).

We estimated the time required for an ionic species to diffuse from the interface of contact to the sample or reference zone using the Einstein relation (eq 1). ${ }^{12}$

$$
\sigma^{2}=2 D t
$$

Assuming one-dimensional diffusion (a reasonable assumption since the thickness of the paper is 
Figure 2. Photographs of a paper-based microfluidic device taken after wicking a pink aqueous solution of $\mathrm{CoCl}_{2}$ and a blue solution of $\mathrm{CuSO}_{4}$ to corresponding zones. The two solutions mixed in the central zone but did not diffuse into the right or left paper zone. The color of the $\mathrm{CoCl}_{2}$ solution became paler after $1 \mathrm{~h}$ and blue after $12 \mathrm{~h}$ as water in the device gradually evaporated. 


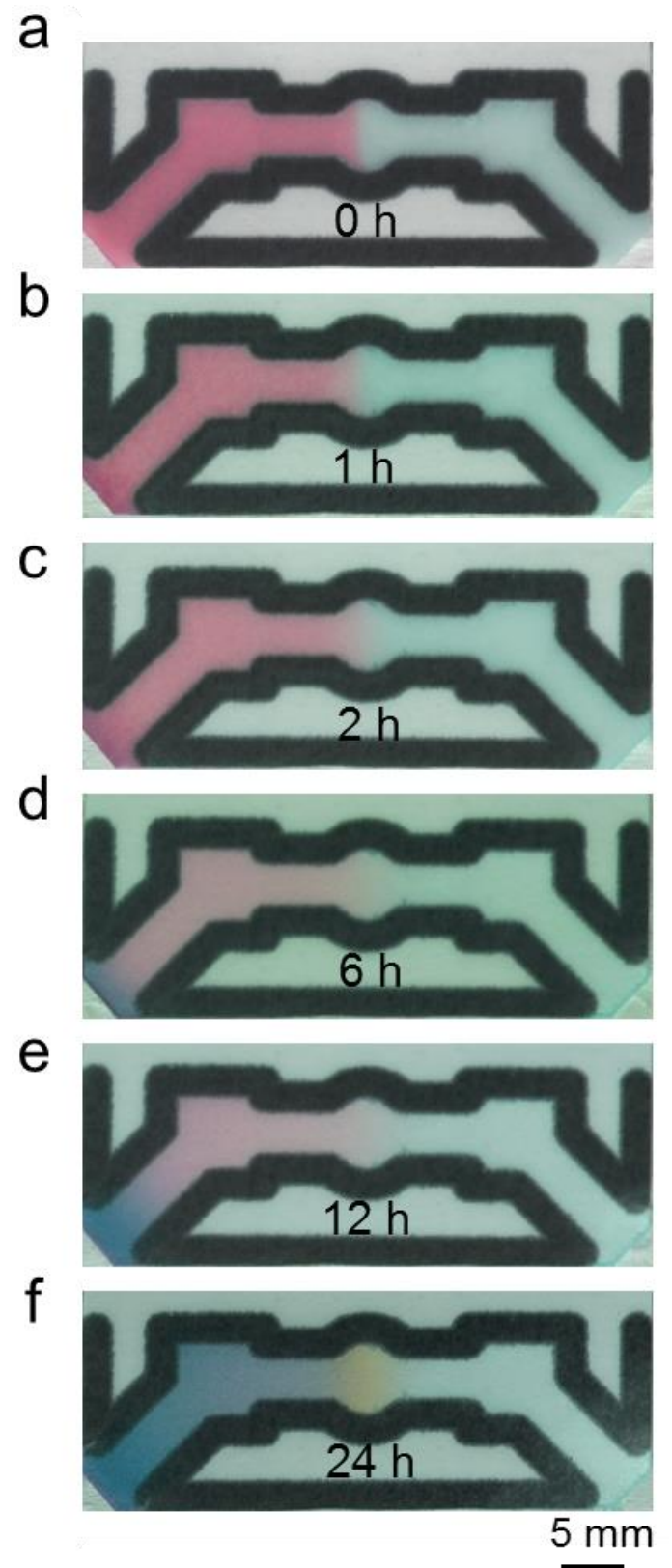


about $200 \mu \mathrm{m}$, and the length of the mixing zone is $\sim 5 \mathrm{~mm}$ ), an ion would diffuse, $\sigma=5 \mathrm{~mm}$, during the time period, $t=10^{3}-10^{5} \sec (\sim 20 \mathrm{~min}-1$ day $)$, for a value of diffusion coefficient (D) expected for an ion (typically $10^{-8}$ to $10^{-10} \mathrm{~m}^{2} / \mathrm{s}$ ). ${ }^{13}$ As these times are much longer than the duration of a typical electrochemical measurement $(<3 \mathrm{~min})$, we conclude that diffusion is unlikely to appreciably change the concentration of ions in the sample and reference zones of the rEPADs. Theoretically, by lengthening the channel by a factor of ten (plausibly using a serpentine pattern to keep the footprint of the rEPAD small), the times required would become very long ( 1 day to $\sim 4$ months).

The hydrated rEPAD therefore allows physical contact and ionic conductivity between the reference and working electrodes, while preventing large-scale convection that would alter the concentrations of analyte and chloride ions in their respective zones (and thus shift the potential of the reference electrode). The central zone operates in a manner similar to the porous plug or frit used in glass-bodied reference electrodes (Figure S2, arrow 6). Other parts in the paper device (labeled by the arrows) perform functions similar to those of their glass-bodied counterparts.

Having determined that the ionic constituents in our reference and sample zones were sufficiently isolated for application in a rEPAD, we used cyclic voltammetry, which provides both qualitative and quantitative information (oxidation/reduction potential, half-cell potential, reaction rates, and concentrations), ${ }^{7}$ to compare the performance of this device (Figure 1b-d, no sealing tape) with that of a conventional, glass, three-electrode system. Figure 3 shows the effect of the reference solution on the peak potentials for the redox reaction of potassium ferri/ferrocyanide $\left(\mathrm{Fe}(\mathrm{CN})_{6}{ }^{3-}(a q)+e^{-} \rightleftarrows \mathrm{Fe}(\mathrm{CN})_{6}{ }^{4-}(a q)\right)$, as measured by cyclic voltammetry. By using rEPADs and a reference solution of $1 \mathrm{M} \mathrm{KCl}$, we estimate anodic and cathodic peak 
Figure 3. Cyclic voltammograms of $1 \mathrm{mM} \mathrm{K}_{3}\left[\mathrm{Fe}(\mathrm{CN})_{6}\right]$ solution at various scan rates obtained from (a) a rEPAD containing a paper-based reference electrode and (b) a commercial electrochemical cell that includes a 3-mm diameter glassy carbon disk working electrode and a conventional $\mathrm{Ag} / \mathrm{AgCl}$ electrode. $1 \mathrm{M}$ aqueous solutions of $\mathrm{KCl}$ and $0.5 \mathrm{M}$ solutions of $\mathrm{KNO}_{3}$ were used as the internal filling solution of the reference electrode and supporting electrolyte in the sample solution, respectively. (c) Cyclic voltammogram of $1 \mathrm{mM} \mathrm{K}_{3}\left[\mathrm{Fe}(\mathrm{CN})_{6}\right]$ solution obtained from a rEPAD using a reference solution of $0.5 \mathrm{M} \mathrm{KNO}_{3}$ instead of $1 \mathrm{M} \mathrm{KCl}$. 


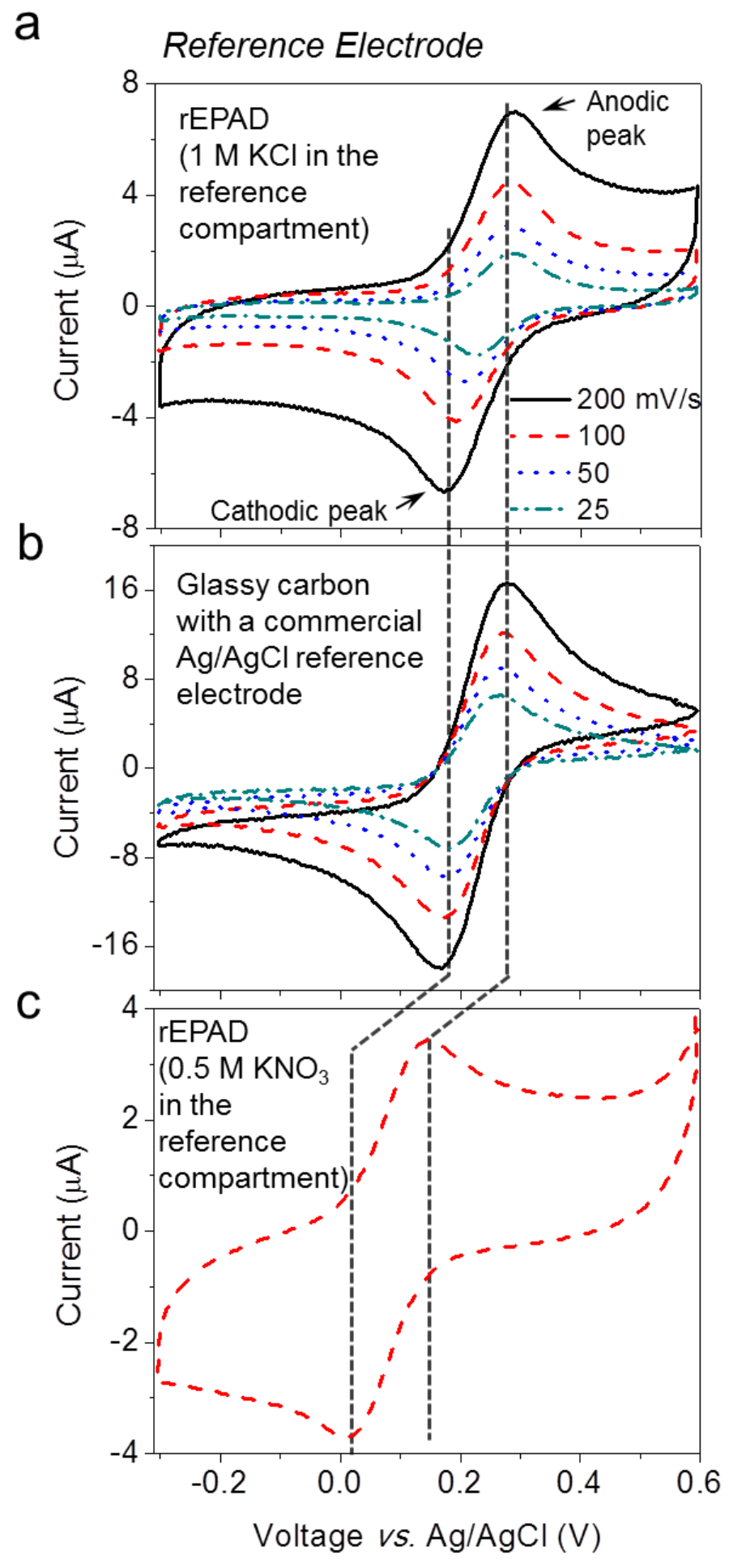


potentials (Figure 3a) for the ferri/ferrocyanide couple of $0.28 \pm 0.01$ and $0.19 \pm 0.02 \mathrm{~V}$, respectively. These results are in good agreement with the peak potentials $(0.28 \pm 0.02$ and 0.17 $\pm 0.02 \mathrm{~V}$ ) obtained using the same sample solution and commercial electrodes (a 3-mm glassy carbon disk working electrode, a platinum-mesh counter electrode, and a commercial $\mathrm{Ag} / \mathrm{AgCl}$ reference electrode).

In contrast, the same rEPADs operating without chloride ions in the reference solution an arrangement similar to that of a $\mathrm{Ag} / \mathrm{AgCl}$ pseudo-reference electrode in direct contact with the sample solution - showed a large shift $(\sim 0.2 \mathrm{~V}$, Figure $3 \mathrm{c})$ in the peak potentials. The peak shift is due to the ill-defined potential of this quasi-reference electrode, and corresponds to a decrease of approximately four orders of magnitude in the concentration of chloride ions in the solution bathing the $\mathrm{Ag} / \mathrm{AgCl}$ electrode, based on calculations from the Nernst equation $(0.059 \mathrm{~V}$ per decade). Under these experimental conditions, the paper-based electrochemical cell is no longer properly referenced, and the voltage information obtained from the voltammetric curves is not accurate. The rEPADs exhibit larger capacitive currents than does the glassy carbon electrode, plausibly because these two systems use different carbon electrodes. The SI provides additional details on the quantitative performance of the rEPADs.

Having established that the rEPADs exhibit a voltammetric performance similar to that of commercial reference cells, we evolved the design of the paper-based devices into a multiplexed system that permits multiple samples to be analyzed simultaneously. Figure 4a shows three separate electrochemical systems in a single device; the sample zones share the same reference electrode without cross contamination. This arrangement would be difficult to achieve with commercial electrochemical cells; an equivalent system would require three separate sample vials, each containing a working and counter electrode, connected via salt bridges to a fourth vial 
Figure 4. (a) Photograph of a multiplexed rEPAD. Three pairs of carbon working and counter electrodes (located at the top, bottom left, and bottom right of the figure) share the same $\mathrm{Ag} / \mathrm{AgCl}$ electrode (bottom middle); this design allows electrochemical analysis of three (or by extension of the design, more) different samples simultaneously. (b), (c), and (d) Cyclic voltammograms obtained from a single rEPAD shown in (a) for analysis of three different analytes: $1 \mathrm{mM}$ potassium hexachloroiridate (IV) $\left(\mathrm{K}_{2} \mathrm{IrCl}_{6}\right)$ in $0.1 \mathrm{M}$ aqueous $\mathrm{KNO}_{3}, 0.5 \mathrm{mM}$ ferrocene $\left(\mathrm{Fe}\left(\mathrm{C}_{5} \mathrm{H}_{5}\right)_{2}\right)$ in acetonitrile solution with $0.1 \mathrm{M} \mathrm{TBAPF}_{6}$, and $1 \mathrm{mM}$ hexaammineruthenium (III) chloride $\left(\mathrm{Ru}\left(\mathrm{NH}_{3}\right)_{6} \mathrm{Cl}_{3}\right)$ in $0.1 \mathrm{M}$ aqueous $\mathrm{KNO}_{3} .10 \mu \mathrm{L}$ each of the sample and reference solutions were added to the respective zones of a device with no sealing tape. The measurements were performed at a scan rate of $50 \mathrm{mV} / \mathrm{s}$. 
a
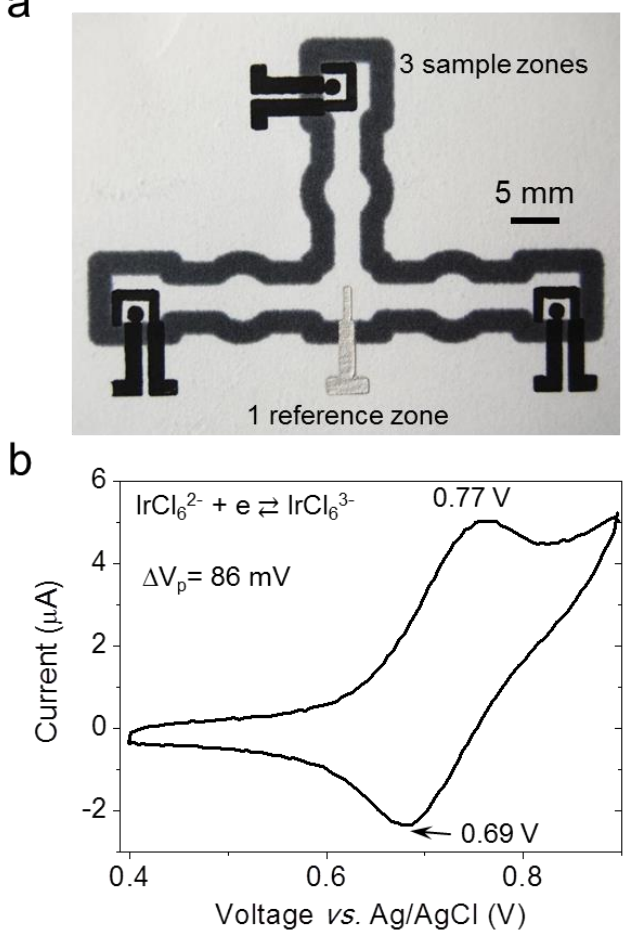

C
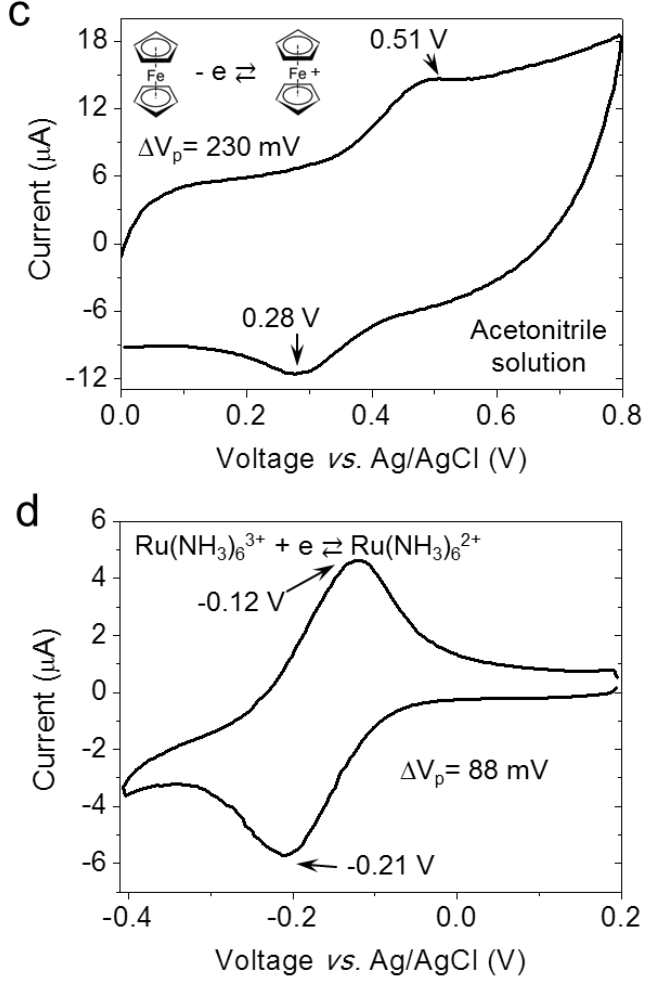
containing the reference electrode.

We tested the multiplexed rEPADs using three different redox couples, $\mathrm{IrCl}_{6}{ }^{2-/ 3-}(1 \mathrm{mM}$ aqueous solution), ferrocene/ferrocenium $\left(0.5 \mathrm{mM}\right.$ acetonitrile solution), and $\mathrm{Ru}\left(\mathrm{NH}_{3}\right)_{6}{ }^{3+/ 2+}(1$ $\mathrm{mM}$ aqueous solution). We chose these samples because they have very different peak potentials, and because they are widely used as standard redox couples for evaluating the performance of electrochemical devices, and as calibrants for unknown species. Figure $4 b-d$ show that the three samples give the peak potentials expected $\left(\sim 0.7^{14}, 0.42^{15}\right.$, and $-0.12^{7} \mathrm{~V}$ respectively, $v s$. $\mathrm{Ag} / \mathrm{AgCl})$.

The peak currents in Figure 4 are close to each other, a consequence of the similar diffusivities of the redox couples. We emphasize that other electrochemical devices based on a $\mathrm{Ag} / \mathrm{AgCl}$ pseudo-reference electrode cannot be used to analyze samples prepared in a solvent, such as acetonitrile, that does not dissolve $\mathrm{KCl}$. The SI discusses the compatibility between acetonitrile and the wax barrier and the peak splitting in organic solutions.

We modified the design of the rEPAD to enable application of the sample and reference solutions without the need for a pipette or injection device; this type of design makes the device suitable for field uses. Figure 5a shows a device that includes inlets at the corners to allow spontaneous wicking of solutions into the relevant zones. We investigated the working lifetime of the rEPADs by performing repeated cyclic voltammetry measurements. The device, which we sealed with tape in order to minimize the rate of solvent evaporation, was functional for approximately $1.5 \mathrm{~h}\left(\right.$ at $\mathrm{T} \sim 23^{\circ} \mathrm{C}, \mathrm{RH} \sim 15 \%$ ) after the application of sample (it takes about $15 \mathrm{~min}$ for the solutions to wick into the device and mix). Figure 5c shows that the peak potentials remain constant over the interval; this stability indicates a consistent concentration of chloride ions at the reference electrode. The reason for the decrease of the peak current with increasing 
Figure 5. (a) Photograph of a sealed rEPAD with the capability of performing both sample application and on-site sample analysis. Microfluidic channels are defined at the corners of the paper device. The dashed lines indicate the boundaries of the tape covered on top of the device. (b) Schematic illustration of an electrochemical cell containing a sealed rEPAD. The rEPAD is attached to a glass slide by double-sided tape, with the electrode side facing the slide, in order to minimize gravity-driven fluid flow, which might cause the contamination of sample or reference zones. Drops of the sample and reference solutions $(<100 \mu \mathrm{L})$ were added to the top of the corresponding inlets to allow controlled and continuous wicking into the device. (c) Time-dependent voltammetric curves obtained from a sealed rEPAD shown in (a) with $1 \mathrm{mM}$ $\mathrm{K}_{3}\left[\mathrm{Fe}(\mathrm{CN})_{6}\right]$ as the sample and $1 \mathrm{M} \mathrm{KCl}$ as the reference solution. 
a

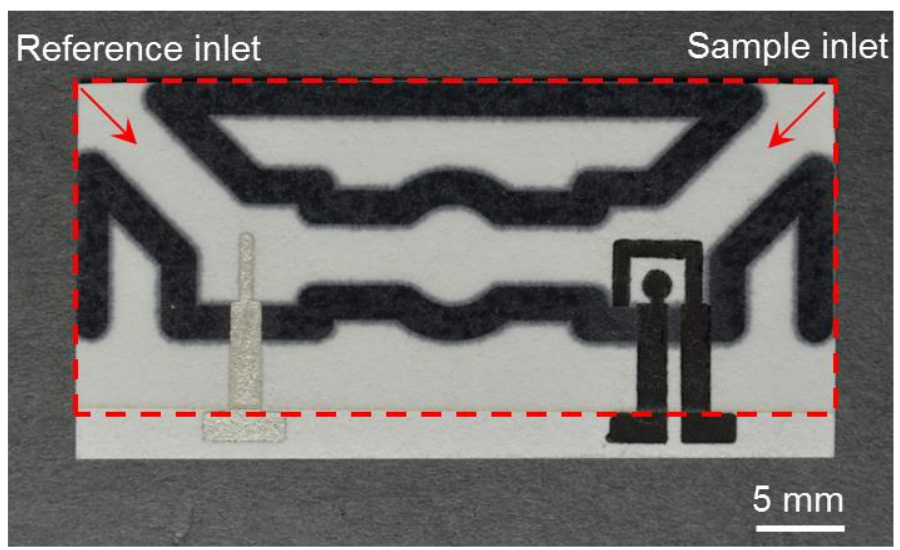

b

\section{Glass slide covered with double-sided tape}
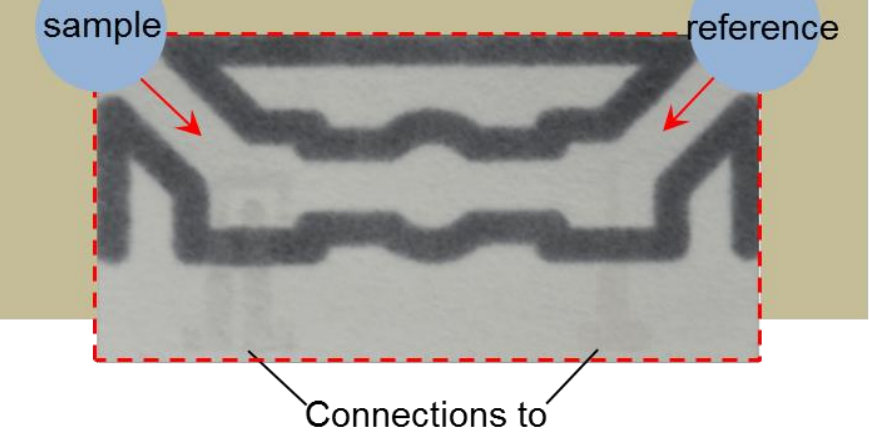

a potentiostat

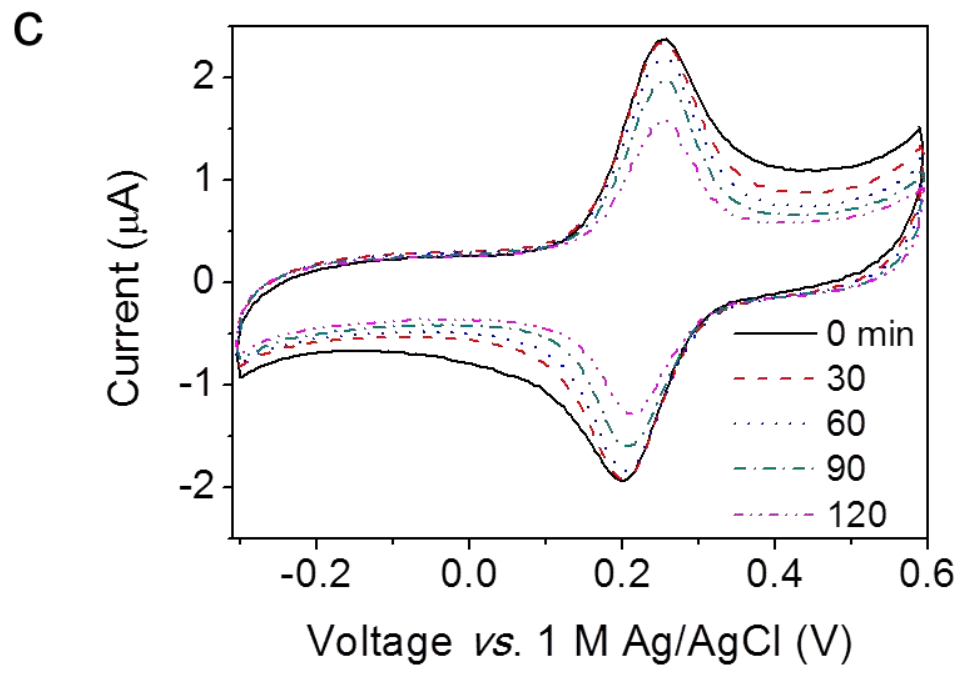


time (>30 min) is not clear at this stage, but may be due to the diffusion of the sample away from the working electrode, adsorption of analyte onto the electrode surface, or reduced ionic conductivity in the device resulting from evaporation of water from the paper channel.

Paper-supported fluids are attractive for electrochemical analyses, and reference electrodes are essential for the development of paper-based electrochemistry. By controlling mass transfer within paper channels (convective during filling; diffusive in use), we have thus designed an electrochemical paper-based analytical device capable of providing accurate voltammetric measurements that are referenced by an electrode with a constant, well-known potential.

The rEPADs have advantages over other miniaturized electrochemical devices: (i) the reference electrode is separate and thus provides a well-defined potential, (ii) the layout can be easily modified, depending on the intended analytical purpose, (iii) the fabrication process does not require complicated thin-film microfabrication processes, and (iv) the device is compatible with samples prepared in some non-aqueous solvents $\left(e . g ., \mathrm{CH}_{3} \mathrm{CN}\right)$. These rEPADs have a simpler structure and a more fully integrated electrochemical reference potential than other paper-based reference electrodes. ${ }^{10}$

These devices are particularly suitable for single-use applications that require a separate reference electrode or an accurate potential, or in cases where chloride ion may interfere with the electrochemical experiment. Combining rEPADs with other, previously demonstrated functions of paper-based devices, including valving, sample pre-concentration, and storage or immobilization of reagents for (bio)chemical assays, ${ }^{16}$ should enable more advanced forms of electrochemical analysis in rEPAD-based systems. The concept may also be extended to the 
construction of electrochemical devices based on other low-cost materials such as nitrocellulose, cloth, Nylon, cotton string, or silk.

\section{Acknowledgements}

This work was supported by the Bill and Melinda Gates Foundation (51308). E.J.M.

thanks the Natural Sciences and Engineering Research Council of Canada for individual support

(NSERC PDF). C.P. acknowledges Generalitat de Catalunya for the fellowship 2011 BE1 00520. 


\section{References}

1. Kimmel, D. W.; LeBlanc, G.; Meschievitz, M. E.; Cliffel, D. E. Anal. Chem. 2012, 84, 685-707.

2. Nie, Z. H.; Nijhuis, C. A.; Gong, J. L.; Chen, X.; Kumachev, A.; Martinez, A. W.; Narovlyansky, M.; Whitesides, G. M. Lab Chip 2010, 10, 477-483.

3. Nie, Z. H.; Deiss, F.; Liu, X. Y.; Akbulut, O.; Whitesides, G. M. Lab Chip 2010, 10, 3163-3169.

4. Carvalhal, R. F.; Kfouri, M. S.; de Oliveira Piazetta, M. H.; Gobbi, A. L.; Kubota, L. T. Anal. Chem. 2010, 82, 1162-1165.

5. a) Dungchai, W.; Chailapakul, O.; Henry, C. S. Anal. Chem. 2009, 81, 5821-5826; b) Apilux, A.; Dungchai, W.; Siangproh, W.; Praphairaskit, N.; Henry, C. S.; Chailapakul, O. Anal. Chem. 2010, 82, 1727-1732.

6. (a) Liu, H.; Xiang, Y.; Lu, Y.; Crooks, R. M. Angew. Chem. Int. Ed. 2012, 51, 6925-6928. (b) Liu, H.; Crooks, R. M. Anal. Chem. 2012, 84, 2528-2532.

7. Bard, A. J.; Faulkner, L. R. Electrochemical Methods: Fundamentals and Applications, 2nd ed.; John Wiley \& Sons: New York, 2001.

8. Lauks, I. R. Acc. Chem. Res. 1998, 31, 317-324.

9. a) Lauks, I. R. Reference Electrode, Method of Making and Method of Using Same. U.S. Patent 4,933,048, 1990; b) Cha, G. S.; Cui, G.; Yoo, J.; Lee, J. S.; Nam, H. Planar Reference Electrode. U.S. Patent 6,964,734 B2, 2005; c) Hsiung, S.-K.; Chou, J.-C.; Sun, T.-P.; Chou, N.-H.; Huang, T.-W. Reference Electrode. U.S. Patent Application Publication 2009/0294284 A1, 2009.

10. a) Diekmann, C.; Dumschat, C.; Cammann, K.; Knoll, M. Sens. Actuators B 1995, 24, 276-278; b) Mroz, A.; Borchardt, M.; Diekmann, C.; Cammann, K.; Knoll, M.; Dumschat, C. Analyst 1998, 123, 1373-1376.

11. Carrilho, E.; Martinez, A. W.; Whitesides, G. M. Anal. Chem. 2009, 81, 7091-7095.

12. Einstein, A. Ann. d. Physik 1905, 17, 549-560. (translated by Cowper, A. D. Methuen: London, 1926.)

13. Grathwohl, P. Diffusion in Natural Porous Media; Kluwer: Boston, 1998.

14. Petrovic, S. Chem. Educator 2000, 5, 231-235.

15. Connelly, N. G.; Geiger, W. E. Chem. Rev. 1996, 96, 877-910.

16. a) Li, X.; Tian, J.; Nguyen, T.; Shen, W. Anal. Chem. 2008, 80, 9131-9134; b) Abbas, A.; Brimer, A.; Slocik, J. M.; Tian, L.; Naik, R. R.; Singamaneni, S. Anal. Chem. 2013, 85, 3977-3983; c) Lankelma, J.; Nie, Z.; Carrilho, E.; Whitesides, G. M. Anal. Chem. 2012, $84,4147-4152$. 


\section{Paper-Based Electroanalytical Devices with an Integrated, Stable}

\section{Reference Electrode}

Wen-Jie Lan ${ }^{\mathrm{a}}$, E. Jane Maxwell ${ }^{\mathrm{a}}$, Claudio Parolo ${ }^{\mathrm{a}, \mathrm{b}}$, David K. Bwambok ${ }^{\mathrm{a}}$, Anand Bala Subramaniam ${ }^{\mathrm{a}}$, and George M. Whitesides ${ }^{\mathrm{a}, \mathrm{c}^{*}}$

${ }^{a}$ Department of Chemistry and Chemical Biology, Harvard University, Cambridge, MA 02138

${ }^{\mathrm{b}}$ Nanobioelectronics \& Biosensors Group, Institut Català de Nanotecnologia, CIN2, Campus $\mathrm{UAB}$, Barcelona, Spain

${ }^{c}$ Wyss Institute for Biologically Inspired Engineering, Harvard University, Cambridge, MA 02138

*Corresponding author E-mail: gwhitesides@gmwgroup.harvard.edu 


\section{Supporting Information}

\section{Experimental}

Chemicals: Carbon ink (E3456) and $\mathrm{Ag} / \mathrm{AgCl}$ ink (E2414) were purchased from Ercon Inc. (Wareham, MA). Potassium nitrate $\left(\mathrm{KNO}_{3}\right)$ was purchased from Alfa Aesar. Potassium chloride (KCl), potassium ferricyanide $\left(\mathrm{K}_{3}\left[\mathrm{Fe}(\mathrm{CN})_{6}\right]\right)$, potassium hexachloroiridate $(\mathrm{IV})\left(\mathrm{K}_{2} \mathrm{IrCl}_{6}\right)$, ferrocene $\left(\mathrm{Fe}\left(\mathrm{C}_{5} \mathrm{H}_{5}\right)_{2}\right)$, hexaammineruthenium (III) chloride $\left(\mathrm{Ru}\left(\mathrm{NH}_{3}\right)_{6} \mathrm{Cl}_{3}\right)$, tetrabutylammonium hexafluorophosphate $\left(\mathrm{TBAPF}_{6}\right)$, and acetonitrile were purchased from Sigma-Aldrich and used as received.

Electrochemical Supplies: Glassy carbon disk working electrodes (3-mm diameter, part \# $\mathrm{CHI} 104)$ and $\mathrm{Ag} / \mathrm{AgCl}$ reference electrodes with $1 \mathrm{M} \mathrm{KCl}$ internal filling solution (Part \# CHI 111) were purchased from CH Instruments, Inc. A platinum gauze (Stock \# 10283, Alfa Aesar) was used as the counter electrode. The working electrodes were polished before voltammetric experiments using a polishing kit (CHI 120) from $\mathrm{CH}$ Instruments.

Fabrication and Use of the Device: Paper-based zones and microfluidic channels were fabricated by patterning chromatography paper (Whatman $1 \mathrm{Chr}$ ) by wax printing. We fabricated electrochemical analytical devices by stencil-printing carbon ink or $\mathrm{Ag} / \mathrm{AgCl}$ ink on the waxprinted paper. We generated a stencil for printing by designing patterns of electrodes using AutoCAD ${ }^{\circledR} 2012$, and cut the pattern into frisket film (Grafix, low tack) using a laser-cutter (VersaLASER VLS3.50, Universal Laser Systems Inc.). We adhered the stencil on top of the paper, and filled the openings of the stencil with ink. We cured the ink by baking the electrodes in an oven at $\sim 100{ }^{\circ} \mathrm{C}$ for $15-20 \mathrm{~min}$. After the ink dried, we removed the film carefully. The reference and sample solutions were added to the corresponding zones using a pipette. For the 
sealed devices, we cut and attached Fellowes ${ }^{\circledR}$ self-adhesive sheet (Staples) to the top and bottom of the device to minimize the effect of evaporation.

Device Geometry: The carbon working electrode is a 1.5-mm diameter disk electrode, while the carbon counter electrode has a larger surface area and surrounds the working electrode (Figure 1). For voltammetric applications, we designed rEPADs such that the carbon working and counter electrodes were stencil-printed on the right side of the device and the $\mathrm{Ag} / \mathrm{AgCl}$ reference electrode $(\mathrm{Ag} / \mathrm{AgCl}$ ink associated with the $\mathrm{KCl}$ solution) on the left side.

Cyclic Voltammetry: We performed cyclic voltammetry (CV) with paper-based devices (or a commercial electrochemical cell) and a potentiostat (Pine Instrument Co., AFCBP1) interfaced to a computer through a PCI-MIO-16E-4 data acquisition board (National Instruments) for potential and current measurements. Voltammetric data were recorded using in-house virtual instrumentation Pinechem 2.7.9a (Pine Instruments).

\section{Convection in the Paper-Based Devices}

Because we pipetted the same small amount of the solution $(10 \mu \mathrm{L})$ to each zone, the mass transfer in the fluid-filled channel due to convection is negligible, i.e., the convection is not strong enough to drive the solution from one side of the device to the other. In fact, even when $10 \mu \mathrm{L}$ was applied only to the left zone, the solution stopped at the right-hand part of the microfluidic channel and did not wick into the right zone. Applications of convective flow in paper-based devices are detailed elsewhere (see reference 1). 


\section{Lifetime of Paper-Based Devices}

We investigated the effect of sealing the devices with tape on the working time of the rEPADs without printed electrodes. Sealed devices require much longer times for the solutions to wick into the central mixing zone, compared to uncovered (Figure S1) devices ( $\sim 15$ min $v s . ~ \sim 0.5$ min), because the air that initially occupies the central channel must diffuse through the tape or through the sides of the device as it is displaced by the sample and reference solutions. The uncovered devices dried completely within 20 minutes, while the sealed devices remained wet for more than $12 \mathrm{~h}$. The color of the paper with $\mathrm{CoCl}_{2}$ solution changed from pink to blue after the water had evaporated. In Figure 2f, the yellow color in the central contact zone might be due to the precipitation of various crystals including $\mathrm{CuCl}_{2}, \mathrm{CoSO}_{4}, \mathrm{CoCl}_{2}$, and $\mathrm{CuSO}_{4}$.

The lifetime for the rEPADs with printed electrodes is significantly shorter than the drying time for the unprinted devices because the electrodes creates a gap between the paper layer and the tape layer that allows water vapor to escape. This gap, however, can be filled by inserting a layer of parafilm or other filler materials, if longer device lifetime is desired.

\section{Cost of Voltammetric rEPADs}

We estimate the cost of materials of rEPADs to be $\sim \$ 0.06$ per device. $\mathrm{Ag} / \mathrm{AgCl}$ ink costs $\$ 1$ per gram, and one gram of ink is sufficient to produce thirty devices by manual stencil printing ( $\$ 0.033$ per device). Graphite ink costs $\$ 0.20$ per gram, and one gram of graphite ink

produces twenty devices by manual stencil printing ( $\$ 0.01$ per device). One page of wax-printed paper ( $20 \mathrm{~cm}$ by $20 \mathrm{~cm}, 28$ devices) costs $\sim \$ 0.50$ ( $\$ 0.018$ per device). Thus, one device costs $\$ 0.061$ in total. We estimate the cost of one device could be as low as $\$ 0.04$ using a mixed 
$\mathrm{Ag} / \mathrm{AgCl} / \mathrm{graphite}$ ink as the reference electrode material. The estimation above is based on the price of commercial products.

\section{Quantitative Measurements by Cyclic Voltammetry}

The stability of the voltage measurement provided by the rEPAD allows us to use cyclic voltammetry to obtain quantitative information about the concentration of analyte. Figure S3a demonstrates a linear relationship between the peak current, $i_{\mathrm{p}}$, at $0.19 \mathrm{~V}(v s . \mathrm{Ag} / \mathrm{AgCl})$ and the concentration of $\mathrm{K}_{3}\left[\mathrm{Fe}(\mathrm{CN})_{6}\right]$ in the range of 1 to $10 \mathrm{mM}$ (a typical range for cyclic voltammetry), in agreement with the Randles-Sevcik equation (eq S1).

$$
i_{p}=\left(2.69 \times 10^{5}\right) n^{3 / 2} A D_{o}^{1 / 2} C_{o}^{*} v^{1 / 2}
$$

In this equation, $n$ is the number of electrons transferred per analyte, $A$ is the electrode area, $D_{o}$ is the diffusion coefficient of the analyte, $C_{o}{ }^{*}$ is the bulk concentration of the analyte, and $v$ is the scan rate of the applied potential $(\mathrm{V} / \mathrm{s})$.

Cyclic voltammetry is not an ideal method for accurate quantitation of electroactive species, because the correction for the non-Faradaic charging current is typically uncertain. When properly referenced, the method does, however, provide an estimate of the analyte concentration; more importantly, the peak potentials, and the shape of the voltammetric curves, provide a qualitative study of redox processes and an understanding of the electrochemical mechanism of the system.

Figure S3b shows that the cathodic peak current is linearly proportional to the square root of the scan rate $\left(v^{1 / 2}\right)$ in the rEPAD; this result indicates a reversible wave and diffusioncontrolled mass transfer towards the working electrode, in accordance with the expected characteristics of the ferri/ferrocyanide redox couple. 
rEPADs for multiplexed voltammetry

The potential differences between the anodic and cathodic peak potentials $\left(\Delta \mathrm{E}_{\mathrm{p}}\right)$ of $\mathrm{Ru}\left(\mathrm{NH}_{3}\right)_{6}{ }^{3+/ 2+}$ and $\mathrm{IrCl}_{6}{ }^{2-/ 3-}$ were 88.4 and $86.4 \mathrm{mV}$, respectively (Figure 4). These values are slightly higher than the theoretical value for an ideal reversible one-electron redox system (59 $\mathrm{mV}$ at $25^{\circ} \mathrm{C}$ ), and may result from the ohmic resistance of the solution. ${ }^{2}$

Acetonitrile was used to dissolve the ferrocene and tetrabutyl ammonium hexafluorophosphate $\left(\mathrm{TBAPF}_{6}\right)$. The wax boundaries contained the acetonitrile within the hydrophilic region as long as only a small volume of solution (several $\mu \mathrm{L}$ ) was used. Other cross-linked polymers that define channels-e.g., SU- $8^{3}$ - would resist dissolution for longer, but were not required here. The applicability of this system is currently limited by evaporation, and the long-term incompatibility of electrochemical organic solvents with the wax barrier and the adhesive tape, but could be improved with further engineering and careful choice of materials.

We speculate that the relatively large capacitive current for the ferrocene/ferrocenium redox couple in acetonitrile (Figure 4c) is due to the interaction between the rough surface of the carbon electrode and the organic solvents used in the paper-based device. The peak splitting $(\sim 0.2 \mathrm{~V})$ is often observed as a consequence of the sluggish, heterogeneous kinetics at the surface of the carbon electrodes. ${ }^{4}$ Quantitative analysis of samples in organic solvents by rEPADs may be affected by the relatively high instability of the interface between the organic solvent and the aqueous reference solution. The signal/noise ratio, however, can be increased upon reducing the scan rate of the voltage. ${ }^{5}$ 
Table S1 Applications of paper-based electroanalytical devices

\begin{tabular}{|l|l|l|}
\hline Reference & Species detected/quantified & Electrochemical method \\
\hline Nie et al. [6,7] & $\begin{array}{l}\text { Glucose, lactate, ethanol, } \\
\text { and heavy-metal ions }\end{array}$ & $\begin{array}{l}\text { Chronoamperometry, cyclic } \\
\text { voltammetry, anodic } \\
\text { stripping voltammetry }\end{array}$ \\
\hline Carvalhal et al. [8] & ascorbic acid and uric acid & Amperometry \\
\hline Henry et al. [9] & $\begin{array}{l}\text { Glucose, lactate, uric acid, } \\
\text { Au, and iron }\end{array}$ & $\begin{array}{l}\text { Chronoamperometry, cyclic } \\
\text { voltammetry, square wave } \\
\text { voltammetry }\end{array}$ \\
\hline Yu et al. [10] & $\begin{array}{l}\text { Immunosensor } \\
\text { (carcinoembryonic antigen } \\
\text { (CEA) et al.) }\end{array}$ & $\begin{array}{l}\text { Differential pulse } \\
\text { voltammetry }\end{array}$ \\
\hline Lankelma et al. [1] & $\mathrm{Glucose}^{\text {and }}$ & Amperometry \\
\hline Liu et al. [11] & ${\mathrm{Adenosine,} \mathrm{glucose,} \mathrm{H}_{2} \mathrm{O}_{2}}^{\text {Amperometry, cyclic }}$ & $\begin{array}{l}\text { Amperom } \\
\text { voltammetry }\end{array}$ \\
\hline Shiroma et al. [12] & paracetamol, 4-aminophenol $^{+}$ & Amperometry \\
\hline Knoll et al. [13] & $\mathrm{K}^{+}, \mathrm{Na}^{+}$ & Potentiometry \\
\hline Novell et al. [14] & $\mathrm{NH}^{+}, \mathrm{K}^{+}, \mathrm{pH}$ & Potentiometry \\
\hline
\end{tabular}


Figure S1. Photographs of a paper-based microfluidic device taken after adding distilled water and pink solution of $\mathrm{CoCl}_{2}$ to corresponding zones. The $\mathrm{CoCl}_{2}$ solution mixed with the water in the central zone but did not diffuse into the left paper zone. The color of the $\mathrm{CoCl}_{2}$ solution became paler after $5 \mathrm{~min}$ and blue after $10 \mathrm{~min}$ as the device gradually dried out because of solvent evaporation. The device was not sealed with tape.

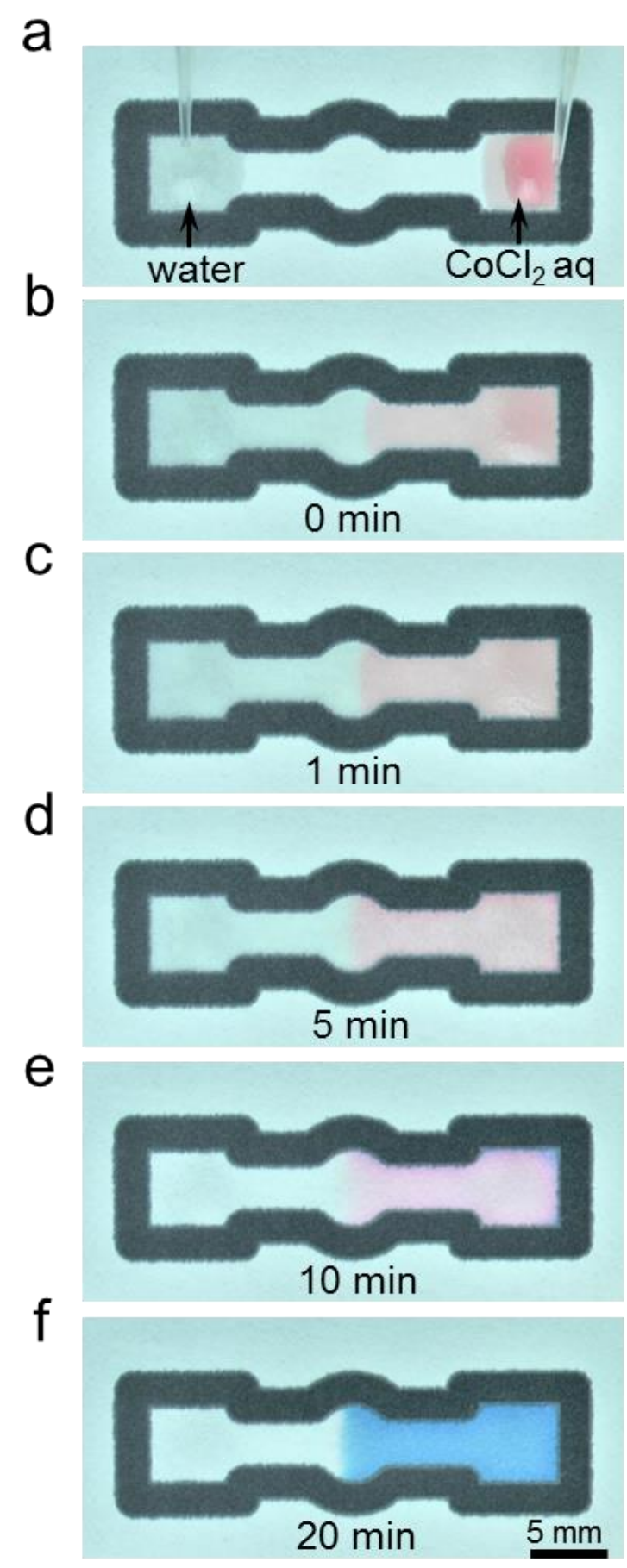


Figure S2. (a) Photograph and schematic illustration of a commercial $\mathrm{Ag} / \mathrm{AgCl}$ reference electrode. (b) Front view and back view of a paper-based electrochemical device (rEPAD). The paper was patterned by wax printing to define the sample zone, central mixing zone, reference zone, and microfluidic channels. The sample and reference zones include stencil-printed carbon and $\mathrm{Ag} / \mathrm{AgCl}$ electrodes, respectively. The arrows with the same number as in (a) refer to similar functions. The dashed lines indicate the approximate boundaries of the carbon and $\mathrm{Ag} / \mathrm{AgCl}$ ink printed on the back.

a

Conventional Ag/AgCl reference electrode

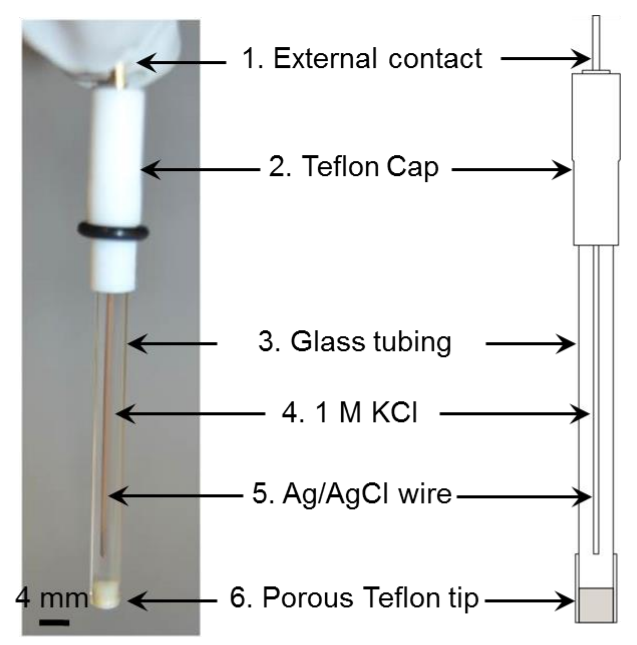

b

Paper-based electrochemical cell Front view

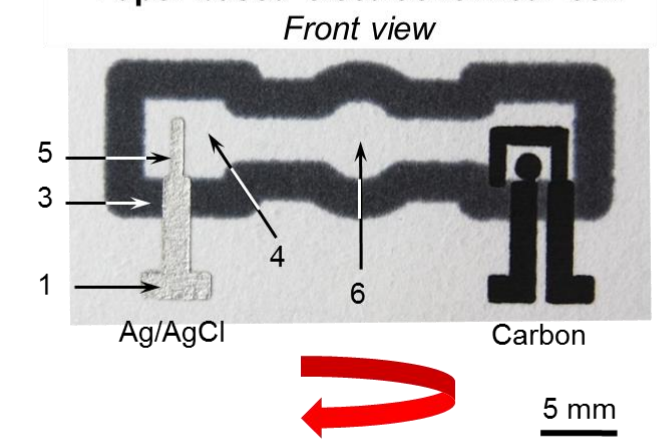

Back view

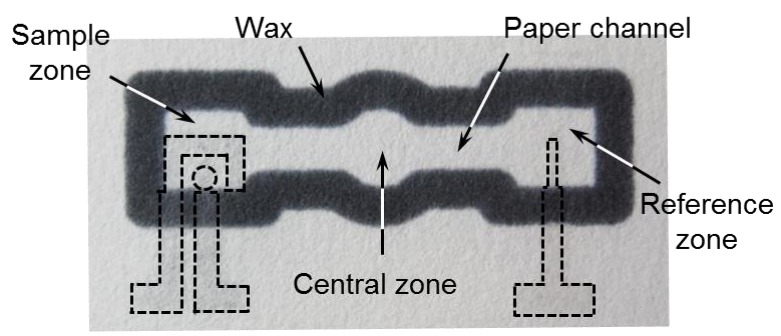


Figure S3. Cathodic peak current $\left(i_{\mathrm{p}}\right)$ as a function of (a) the concentration of $\mathrm{K}_{3}\left[\mathrm{Fe}(\mathrm{CN})_{6}\right]$ and (b) the square root of the scan rate $\left(v^{1 / 2}\right)$ for cyclic voltammetry experiments conducted on rEPADs. The solid lines represent a linear fit to (a) with regression equation: $y=0.16+1.4 x\left(R^{2}\right.$ $=0.998, \mathrm{n}=7)$, and a linear fit to $(\mathrm{b})$ in e with regression equation: $\mathrm{y}=-0.65+0.42 \mathrm{x}\left(\mathrm{R}^{2}=\right.$ $0.995, \mathrm{n}=7)$.
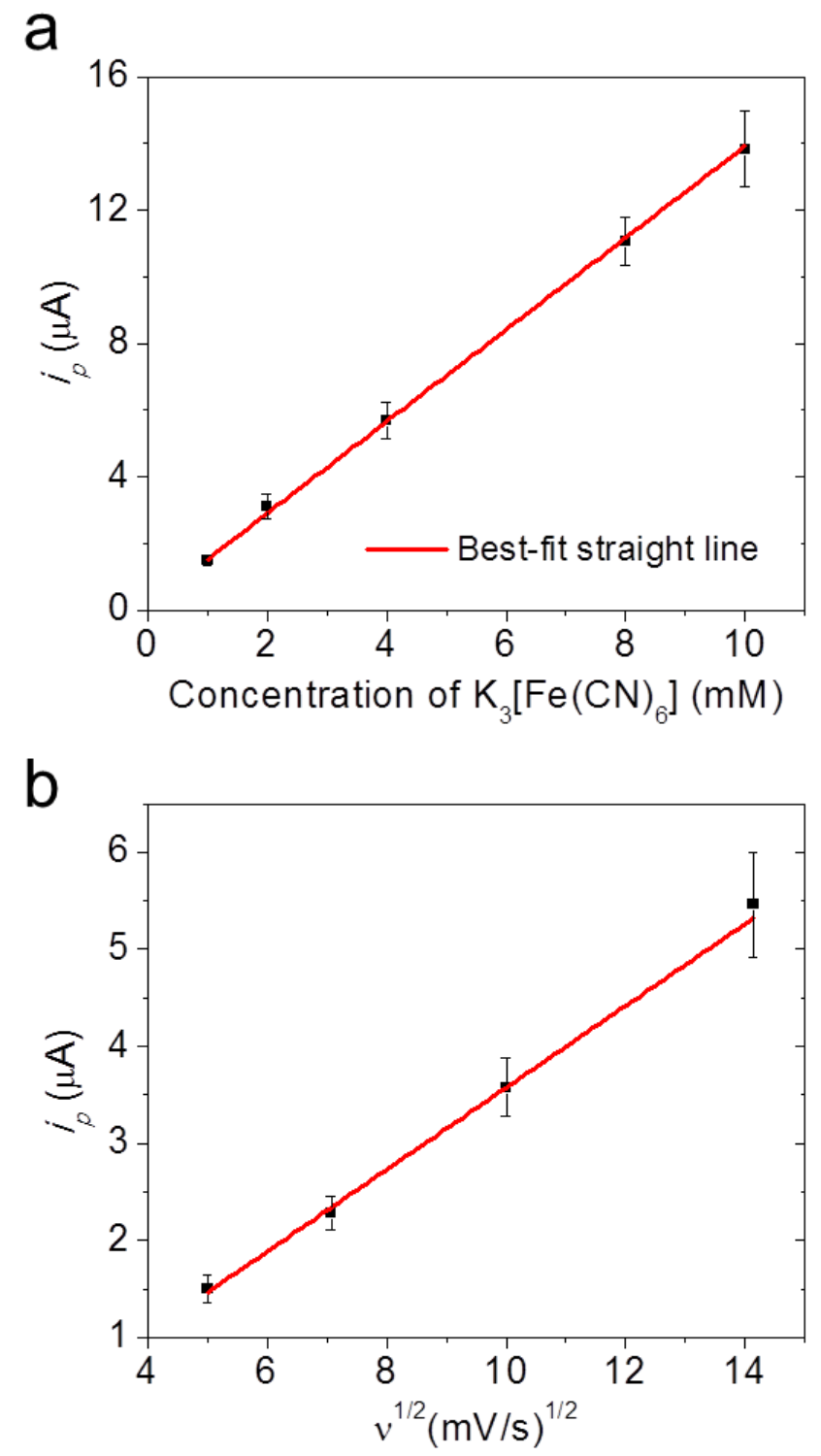


\section{References}

1. Lankelma, J.; Nie, Z.; Carrilho, E.; Whitesides, G. M. Anal. Chem. 2012, 84, 4147-4152.

2. Flanagan, J. B.; Margel, S.; Bard, A. J.; Anson, F. C. J. Am. Chem. Soc. 1978, 100, 42484253.

3. SU-8 2000.5-2015 Data Sheet, MicroChem Corp. (http://www.microchem.com/ProdSU82000.htm)

4. Wang, J.; Pedrero, M.; Sakslund, H.; Hammerich, O.; Pingarron, J. Analyst 1996, 121, 345-350.

5. Bard, A. J.; Faulkner, L. R. Electrochemical Methods: Fundamentals and Applications, 2nd ed.; John Wiley \& Sons: New York, 2001.

6. Nie, Z. H.; Nijhuis, C. A.; Gong, J. L.; Chen, X.; Kumachev, A.; Martinez, A. W.; Narovlyansky, M.; Whitesides, G. M. Lab Chip 2010, 10, 477-483.

7. $\quad$ Nie, Z. H.; Deiss, F.; Liu, X. Y.; Akbulut, O.; Whitesides, G. M. Lab Chip 2010, 10, 3163-3169.

8. Carvalhal, R. F.; Kfouri, M. S.; de Oliveira Piazetta, M. H.; Gobbi, A. L.; Kubota, L. T. Anal. Chem. 2010, 82, 1162-1165.

9. (a) Dungchai, W.; Chailapakul, O.; Henry, C. S. Anal. Chem. 2009, 81, 5821-5826. (b) Dungchai, W.; Chailapakul, O.; Henry, C. S. Analyst 2011, 136, 77-82. (c) Apilux, A.; Dungchai, W.; Siangproh, W.; Praphairaskit, N.; Henry, C. S.; Chailapakul, O. Anal. Chem. 2010, 82, 1727-1732.

10. (a) Zang, D.; Ge, L.; Yan, M.; Song, X.; Yu, J. Chem. Commun. 2012, 48, 4683-4685. (b) Wang, P.; Ge, L.; Yan, M.; Song, X.; Ge, S.; Yu, J. Biosens. Bioelectron. 2012, 32, 238243.

11. (a) Liu, H.; Xiang, Y.; Lu, Y.; Crooks, R. M. Angew. Chem. Int. Ed. 2012, 51, 69256928. (b) Liu, H.; Crooks, R. M. Anal. Chem. 2012, 84, 2528-2532.

12. Shiroma, L. Y.; Santhiago, M.; Gobbi, A. L.; Kubota, L. T. Anal. Chim. Acta 2012, 725, 44-50.

13. Dumschat, C.; Borchardt, M.; Diekmann, C.; Cammann, K.; Knoll, M. Sens. Actuators B 1995, 24-25, 279-281.

14. Novell, M.; Parrilla, M.; Crespo, G. A.; Rius, F. X.; Andrade, F. J. Anal. Chem. 2012, 84, 4695-4702. 